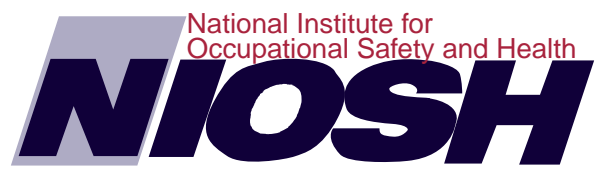

\title{
A Model for Research on
}

\section{Training \\ E ffectiveness}

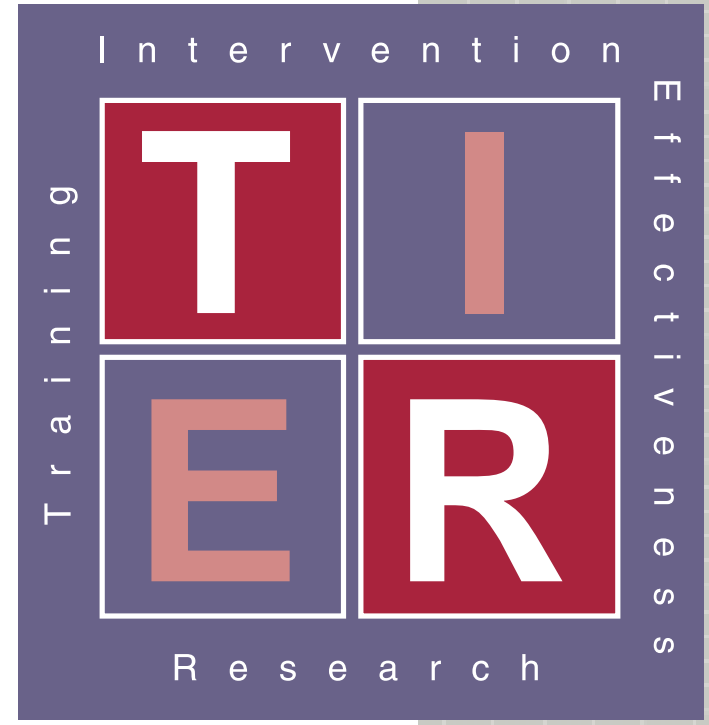

U.S. DEPARTMENT OF HEALTH AND HUMAN SERVICES Public Health Service

Centers for Disease Control and Prevention

National Institute for Occupational Safety and Health

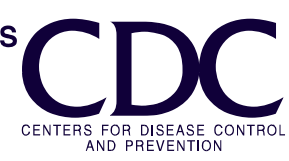




\section{DISCLAIMER}

Mention of any company or product does not constitute endorsement by the National Institute for Occupational Safety and Health.

This document is in the public domain and may be freely copied or reprinted.

Copies of this and other NIOSH documents are available from

National Institute for Occupational Safety and Health

Publications Dissemination

4676 Columbia Parkway

Cincinnati, OH 45226-1998

Fax number: (513) 533-8573

Telephone number: 1-800-35-NIOSH (1-800-356-4674)

E-mail: pubstaft@cdc.gov

To receive other information about occupational safety and health problems, call

1-800-35-NIOSH (1-800-356-4674), or visit the NIOSH Web site at www.cdc.gov/niosh

October 1999

DHHS (NIOSH) Publication No. 99-142 


\section{CONTENTS}

1. Occupational Safety and Health Training $\ldots \ldots \ldots \ldots \ldots$ 1

Background $\ldots \ldots \ldots \ldots \ldots \ldots \ldots \ldots \ldots \ldots \ldots \ldots \ldots \ldots \ldots \ldots \ldots \ldots$

Training Perspectives in the United States . . . . . . . . 2

2. What Makes Training Effective? .............. 5

Introduction $\ldots \ldots \ldots \ldots \ldots \ldots \ldots \ldots \ldots \ldots \ldots \ldots \ldots \ldots \ldots \ldots \ldots$

Approaches to Effectiveness Research $\ldots \ldots \ldots \ldots \ldots \ldots \ldots$

The TIER Model $\ldots \ldots \ldots \ldots \ldots \ldots \ldots \ldots \ldots \ldots$

Study Variables $\ldots \ldots \ldots \ldots \ldots \ldots \ldots \ldots \ldots \ldots \ldots \ldots$

Independent Variables $\ldots \ldots \ldots \ldots \ldots \ldots \ldots$

Dependent Variables .................... 8

Modifying Variables $\ldots \ldots \ldots \ldots \ldots \ldots \ldots \ldots$

Intervening Variables $\ldots \ldots \ldots \ldots \ldots \ldots \ldots \ldots$

Confounding Variables $\ldots \ldots \ldots \ldots \ldots \ldots \ldots$

Four Stages of the Tier Model . . . . . . . . . . . . . . . 9

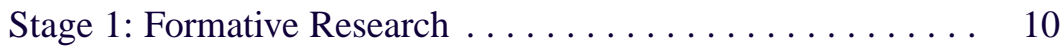

Stage 2: Process Research ............... 10

Stage 3: Outcome Research ................. 12

Stage 4: Impact Assessment $\ldots \ldots \ldots \ldots \ldots \ldots \ldots \ldots$

3. Application of TIER Model to Occupational

Safety and Health Training $\ldots \ldots \ldots \ldots \ldots \ldots \ldots \ldots \ldots$

Emerging Issues $\ldots \ldots \ldots \ldots \ldots \ldots \ldots \ldots \ldots \ldots \ldots$

Readiness ............................ 19

References $\ldots \ldots \ldots \ldots \ldots \ldots \ldots \ldots \ldots \ldots \ldots \ldots \ldots \ldots \ldots$ 


\section{Acknowledgments}

This document was prepared by Gregory P. Loos, Ed.D., and Thaddeus Fowler, Ed.D., Education and Information Division (EID) of the National Institute for Occupational Safety and Health (NIOSH). Karen Miles, Ph.D., helped develop the model concept.

The authors wish to thank Richard Carlson, Pauline Elliott, and Anne Stirnkorb (NIOSH, Education and Information Division) for their contributions to the graphics and design of this document. 


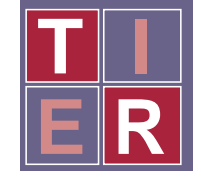

\section{Occupational Safety and Health Training}

\section{Background}

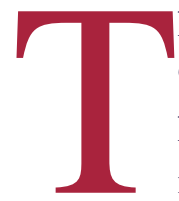

he Occupational Safety and Health Act of 1970 (Public Law 91-596) was enacted to assure, so far as possible, safe and healthful working conditions for every working man and woman in the Nation. The Act mandated improved research, regulation, and training aimed at reducing the incidence of occupational injury and illness. To achieve these goals, provisions were made for two distinct Federal agencies: the National Institute for Occupational Safety and Health (NIOSH) and the Occupational Safety and Health Administration (OSHA). OSHA develops and promulgates safety and health regulations in the workplace. NIOSH serves the occupational safety and health research needs of the Federal government and the public. Both agencies are charged with delivering occupational safety and health training.

The act states the following about occupational safety and health training:

[The Federal government] . . . shall conduct, directly or by grants or contracts . . . educational programs to provide an adequate supply of qualified personnel to carry out the purposes of this Act ... [and] is also authorized to conduct directly, or by grants or contracts, short-term training of personnel engaged in work related to ... responsibilities under this Act ... [and] provide for the establishment and supervision of programs for the education and training of employers and employees in the recognition, avoidance, and prevention of unsafe or unhealthful working conditions in employments covered by this Act [29 USC* 1900].

In response to this mandate, NIOSH and OSHA have provided direct occupational safety and health training and sponsored training programs within universities, labor unions, secondary schools, and other institutions. Currently, NIOSH administers training through a network of colleges and universities supported by the Institute. Internally, NIOSH researches the effectiveness and impacts of training. This document offers a guide to such research. 


\section{Training Perspectives in the United States}

More than 100 OSHA standards for controlling workplace hazards contain requirements for worker training to reduce risk factors for injury and disease. Other standards limit certain jobs to workers considered competent by virtue of special training [Cohen and Colligan 1998]. However, the documented outcomes of occupational safety and health training are varied and inconclusive. Moreover, the newly proposed OSHA Occupational Safety and Health Program Rule [DOL 1998] redirects compliance audits to training outcomes and impacts (in the past, such audits focused on hours of training delivered). Given this shift in priority, research will be needed to identify strategies for improving the measurable performance of mandated training programs.

Each year, corporate America provides nearly 2 billion hours of training to approximately 60 million employees at a cost of $\$ 55$ to $\$ 60$ billion [Industry report 1997]. Effectiveness research can maximize the impact of this investment on worker safety, productivity, and profits.

To equip America's workforce with the skills necessary in today's economy, the U. S. Departments of Education and Labor have recently cosponsored several initiatives that reflect the national importance of worker training. Examples of such programs follow:

School-to-Work, established through the School-to-Work Opportunities Act of 1994, links school programs to local businesses and civic organizations. Employers and educators combine resources to provide skill training and job placement. Currently, funding for School-to-Work programming is being transferred to State and local authorities.

Tech-Prep is a broad initiative of the Carl D. Perkins Vocational and Technical Education Act of 1998. This program teaches students transferrable skills and abilities that employers favor when selecting personnel. These include the "hard" skills needed to perform tasks and the "soft" skills such as problem solving, teamwork, and leadership.

National Skills Standards Board (NSSB), a provision of the National Skills Standards Act of 1994, establishes competency standards for defined occupational sectors. The goal of NSSB is to help schools provide relevant vocational education, reduce job training costs, and fill industry's needs for skilled workers. 
The Workforce Investment Act of 1998 (WIA) takes a holistic approach to training. WIA has consolidated 60 Federal job training programs into three block grants targeting disadvantaged youth, adult workers, and families. WIA requires participating programs to integrate job training, placement, and family support services into a "one-stop" system of career development.

- The American Competitive and Workforce Improvement Act of 1999 funds training programs in mathematics, engineering, and science. Such programs are designed to prepare the domestic workforce for high-technology work environments and to reduce U.S. dependence on imported labor.

These initiatives illustrate the growing emphasis on occupational skill development and worker readiness. Although it may seem logical to assume that an educated workforce will be safer and more productive, researchers do not fully understand precisely how training influences the actions of workers. Educational research should be conducted to investigate this relationship so that optimum training effectiveness can be achieved.

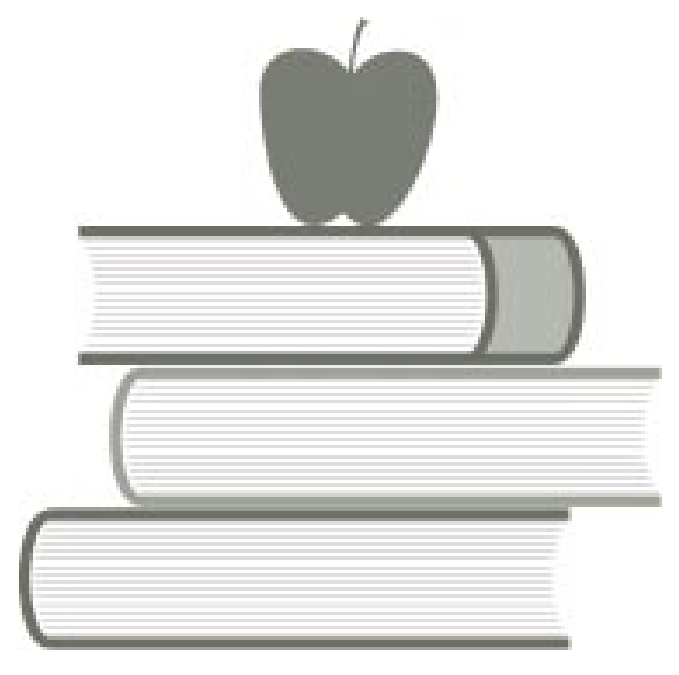




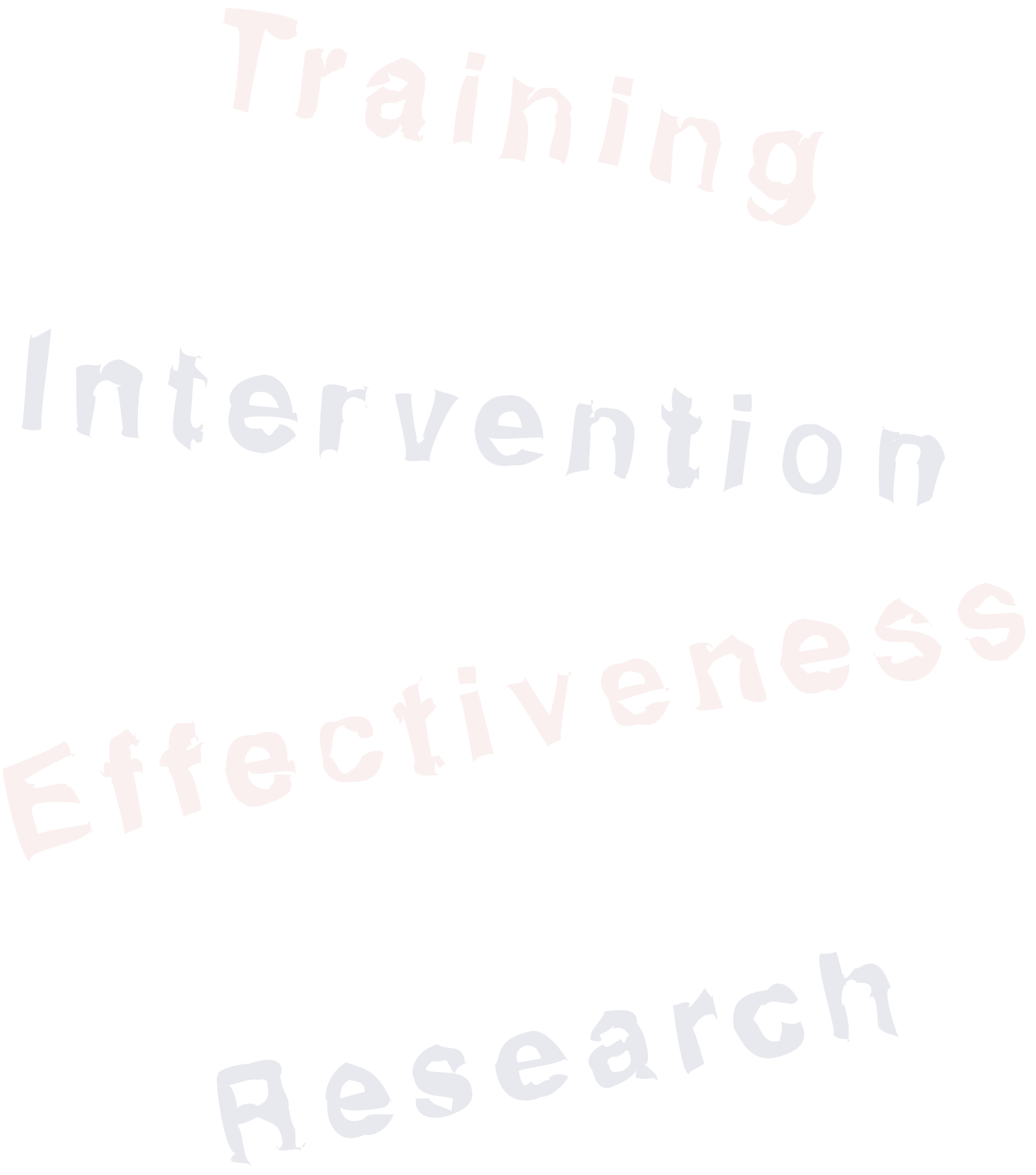




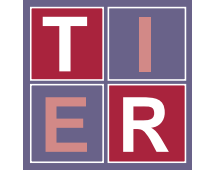

\section{What Makes Training Effective?}

\section{Introduction}

Training is widely understood as communication directed at a defined population for the purpose of developing skills, modifying behavior, and increasing competence. Generally, training focuses exclusively on what needs to be known. Education is a longer-term process that incorporates the goals of training and explains why certain information must be known. Education emphasizes the scientific foundation of the material presented. Both training and education induce learning, a process that modifies knowledge and behavior through teaching and experience. The research model described here pertains to both training and education. Therefore, in this document, "training" refers to both processes.

In contrast to informal training (which is embedded in most instances of human exchange), formal training interventions have stated goals, content, and strategies for instruction. Our intent is to offer a general approach to intervention effectiveness research that addresses formal training across settings and topics. The model integrates primary and secondary data collection with qualitative and quantitative analyses so that the benefits of each research technique can be applied to the evaluation of training effectiveness.

Training intervention effectiveness research is needed to (1) identify major variables that influence the learning process and (2) optimize resources available for training interventions. Logical and progressive study models are best suited to identify the critical elements and causal relationships that affect training effectiveness and efficiency.

In training research, it is often difficult to arrive at definitive answers. Typically, many variables minimize effects and make results difficult to interpret. Furthermore, the amount of variance attributed to any one variable is usually small. Therefore, if training is to be an essential component of planned interventions, a uniform system of research is needed to explain how training is made effective and to indicate how resources for training should be organized.

The model described here recognizes that formal training interventions are affected by several real-world factors such as uneven resource availability across training settings 
and differing levels of experience and expertise among instructors. Accordingly, training evaluation research should be conducted in the field where possible in order to incorporate these variables into the study of effectiveness.

Established techniques (such as qualitative study methods and quasi-experimental research designs) are available to deal with the difficulties of field research [Miles and Huberman 1984; Tuckman 1972]. These techniques enable researchers to develop evaluation designs appropriate for investigating many of the critical elements of effective training. As presented, the model provides a framework in which to practice these methodologies. Consequently, routine implementation of the model will lead to increased consistency and logic across training evaluation studies-and to generalization of research findings to multiple training circumstances.

\section{Approaches to Effectiveness Research}

Two approaches to training intervention effectiveness research can be used to uncover results without committing extraordinary resources. One approach employs triangulation (use

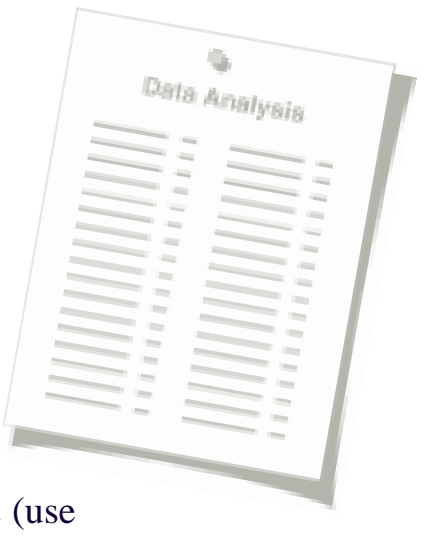
of multiple data sources and methods) to gather data from prospective end users and combine qualitative data (e.g., from focus groups, interviews, and observations) with various forms of quantitative data (e.g., those from controlled study situations) [Crabtree and Miller 1992]. Data are then used to assemble a valid argument for the interpretation of results.

The other approach to effectiveness research explores cause-and-effect relationships that are pertinent to the learning process and have been established through years of training research, including meta-analyses [Borich 1998]. For the purpose of training assessment, the cause-andeffect relationships of interest are those between the process, outcomes, and impacts of training. In these relationships, the process variables (e.g., training methods and mediums used) are indicators of the outcomes (e.g., knowledge gained among trainees). The key to identifying the essential elements of effective training lies in understanding the correlation of these variables with the intended impact of training (e.g., diffusion of new skills and abilities) [Cohen and Colligan 1998].

For example, the most important goal of occupational safety and health training is the long-term reduction of injury and illness among workers. However, a longitudinal study does not meet the immediate evaluation needs of training interventions, and resources for such studies are not readily available. Therefore, occupational safety and health training research usually focuses on representative outcomes (e.g., workers' statements of behavioral intent) that are believed to accurately project unrealized impacts. Representative outcomes include direct results (such as improved attitudes toward risk reduction and hazard control) and intermediate variables (such as changes in work practices among workers who have received training). 
Still, intervening and modifying variables complicate results, even in short-term training studies. However, since much is known about the relationships between the process of instruction and the product of learning [Borich 1998], it is possible to assess the quality of the process variables and thereby predict the product. Later stages of training intervention research use controlled studies followed by correlation and longitudinal studies. In these succeeding stages, statistical data are used to assess impact.

To identify the elements of training that are critical to increased effectiveness, the Education and Information Division (EID) of the National Institute for Occupational Safety and Health (NIOSH) has developed a research guide known as the training intervention effectiveness research model (TIER model).

\section{The TIER Model}

The TIER model is designed to (1) take into account the challenges of identifying factors that make the training-learning-action continuum successful, (2) logically match research efforts with the nature of the question(s) at hand, (3) minimize training and curriculum development risks, and (4) concentrate research resources. The TIER model is applicable to training interventions on a variety of topics.

\section{Study Variables}

The TIER model regards five types of study variables as integral to training effectiveness research: independent, dependent, modifying, intervening, and confounding variables (see Figure 1). Studies depend on access to measurable data for these variables.

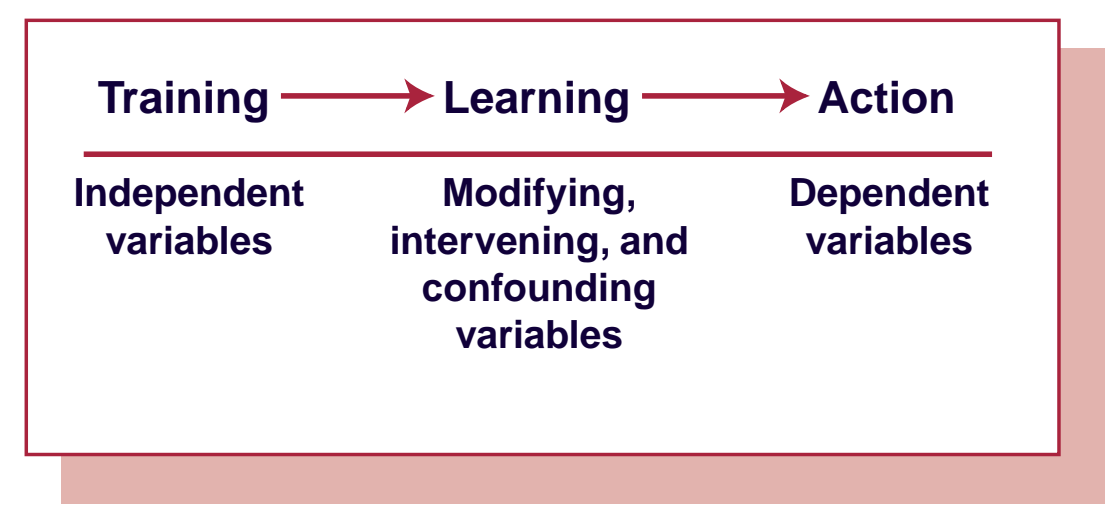

Figure 1. Variables influencing the effectiveness of the training-learning-action continuum. 


\section{Independent Variables}

Independent variables are the manipulated variables - that is, the training inputs and activities that are implemented and studied. They are presumed to cause or influence certain training outcomes. Depending on the study, independent variables could include timing, format, and location of training as well as modifications to the training rationale, content, or educational approach under study [Gagné 1985].

\section{Dependent Variables}

Dependent variables are the intended aims of training, which are expected to result from exposure to the independent variables. As exposure varies, results may differ, allowing effectiveness to be measured. The TIER model differentiates between dependent variables that are immediate effects of training (termed "outcomes") and dependent variables that are later-emerging effects of training (termed "impacts") [Mohr 1992].

Sample outcomes of training include participant satisfaction with the course; changes in knowledge, attitude, and behavioral intent; and demonstrated skills or abilities. Sample impacts of training include the following: diffusion of course material into the field, retention of knowledge and attitudes, transfer of behavioral intent into practice, application of learned skills and abilities, transfer of training to new populations, and acceptance of instructional content as normal operating procedure.

\section{Modifying Variables}

Modifying variables can modify the influence of independent variables on dependent variables. Therefore, to preserve the integrity of results, modifying variables must be controlled or neutralized for all study conditions. Learner variables (age, sex, socioeconomic status, etc.), trainer variables (experience, teaching style, etc.), and context variables (class size, classroom instruction versus apprenticeship training, etc.) can all modify learning outcomes. Typically, when modifying variables are suspected, research design techniques such as stratified sample selection can be used to control and study their effects on dependent variables.

\section{Intervening Variables}

Intervening variables are inferred concepts intended to explain the processes between stimulus (independent variables) and response (dependent variables). Intervening variables cannot be meaningfully observed, manipulated, or measured. In educational research, such constructs frequently relate to learner attentiveness, ability and motivation to learn, learning style, and individual coping mechanisms when ingesting new material [Dunn and Griggs 1988]. Intervening variables may also pertain to (1) the trainer's ability to engage learners with the subject matter, and (2) contextual attributes such as the structure and formality of the educational environment. Random selection and assignment of subjects are presumed to control for most intervening variables. 


\section{Confounding Variables}

Factors beyond the learner's control can influence training outcomes. These confounding variables act synergistically with the independent variables and thus are suspected of altering the effects on the dependent variables. Therefore, confounding variables can bias the interpretation of data. Possible confounding variables in effectiveness research are changes in institutional policy, implementation of new technologies, and other nontraining factors that could influence dependent variables. Again, controls applied to sample selection, research design, and data analysis can identify and compensate for the effects of concurrent exposure to multiple causative agents.

\section{Four Stages of the TIER Model}

The TIER model systematically structures training effectiveness research across four stages (see Figure 2). Stages 1 and 2 are components of formative evaluation in which the objectives and processes of training are conceptualized, drafted, and refined. During these stages, researchers explore instructional alternatives to determine which are most appropriate for study. Stages 3 and 4 are components of summative evaluation-a systematic attempt to determine whether the fully developed training intervention is meeting its objectives as planned or desired [Scriven 1967, 1991]. The four stages of the TIER model are explained in detail as follows.

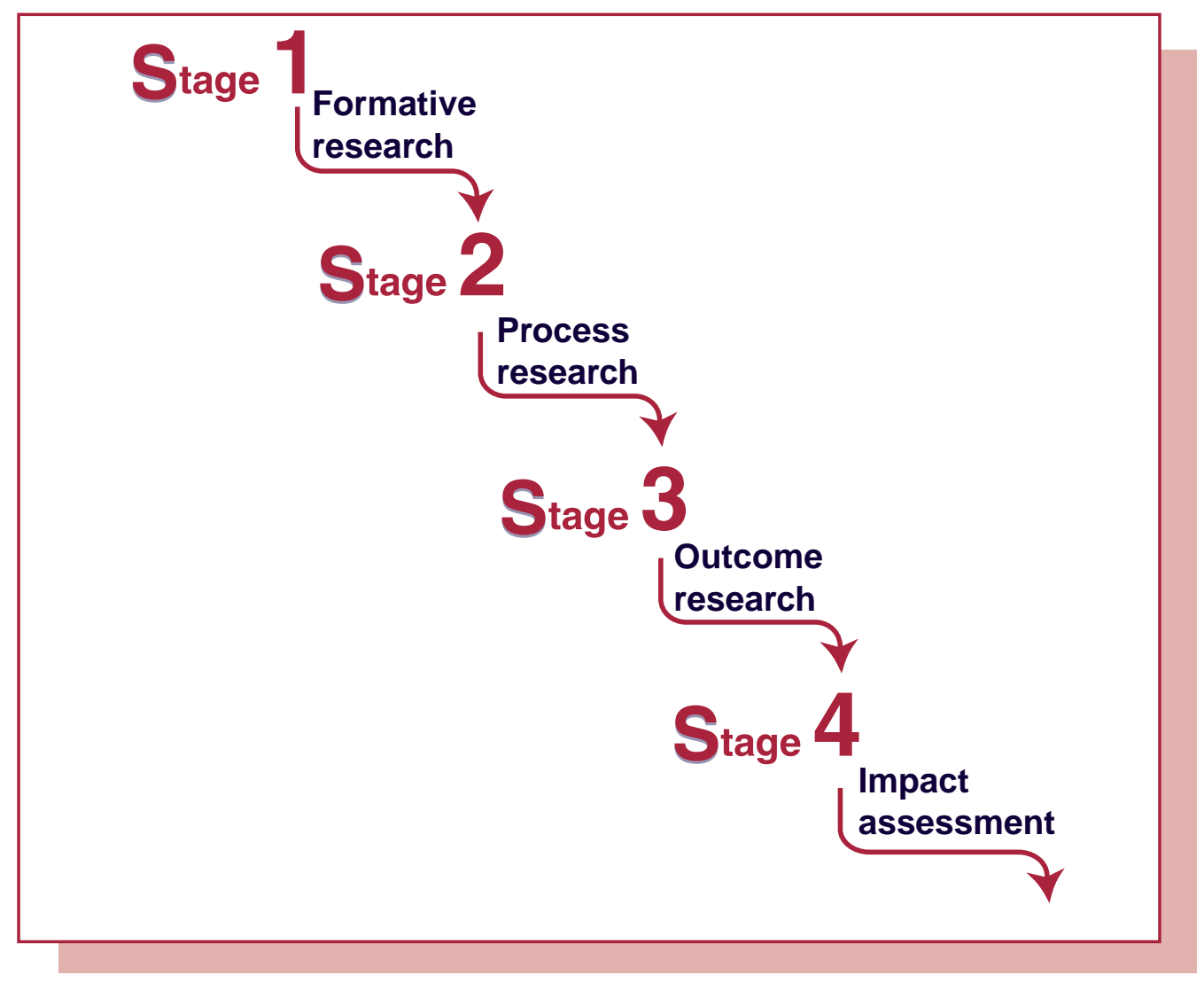

Figure 2. Logical and progressive stages for training intervention effectiveness research. 


\section{Stage 1: Formative Research}

In Stage 1, training efforts are conceived, reviewed, and structured. Typically, this stage involves the following research questions:

What are the needs and how are they determined?

What are the target populations served by the training?

How do the goals and objectives of the training relate to identified needs?

How will the attainment of these goals be assessed?

What instructional approach should be taken?

Stage 1 helps researchers understand the population to be served, its needs, and the aims of instruction. Also in this stage, assessment instruments and training materials are drafted. During formative research, TIER model users collaborate with (1) end users to ascertain preferred communication channels, learning styles, and instructional mediums; (2) content experts to provide technical and policy reviews; and (3) training professionals to perform pedagogic and instructional reviews (see Figure 3).

\section{Stage 2: Process Research}

In Stage 2, draft training materials, proposed instructional approaches, and research instruments are field tested in pilot sites. Several research questions are typical for this stage.

What modifications are needed?

Are the materials educationally and pedagogically sound?

Are the assessment instruments valid?

Is there enough confidence in the approach to warrant higher-cost enhancements (e.g., video, multimedia) and wider distribution of materials?

The qualitative and quantitative information that is collected from the field testing leads to the modification of materials and increased confidence in the approaches taken. Two field tests are desirable for refining the curriculum materials, delivery mechanisms, and assessment instruments before a large-scale, controlled evaluation study begins. Feedback from the first field test is used to redraft pilot materials for a second study. Information gained from the second test is used to finalize the materials for controlled intervention studies in the next stage of the TIER model. To minimize development costs, complex curricular enhancements (such as video) are not prepared until the second study. 
1. Identify and characterize needs:

- Population-based needs

- Service-based needs

- Professional/normative needs

- Consumer-perceived/felt needs

- Cost-based demand

\section{$\downarrow$}

2. Establish training goals and objectives.

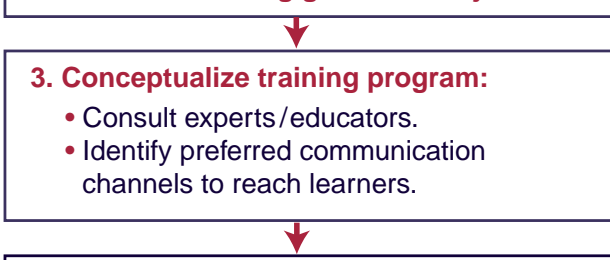

4. Draft instructional materials:

- Analyze training task.

- Develop curriculum.

- Design instructional format.

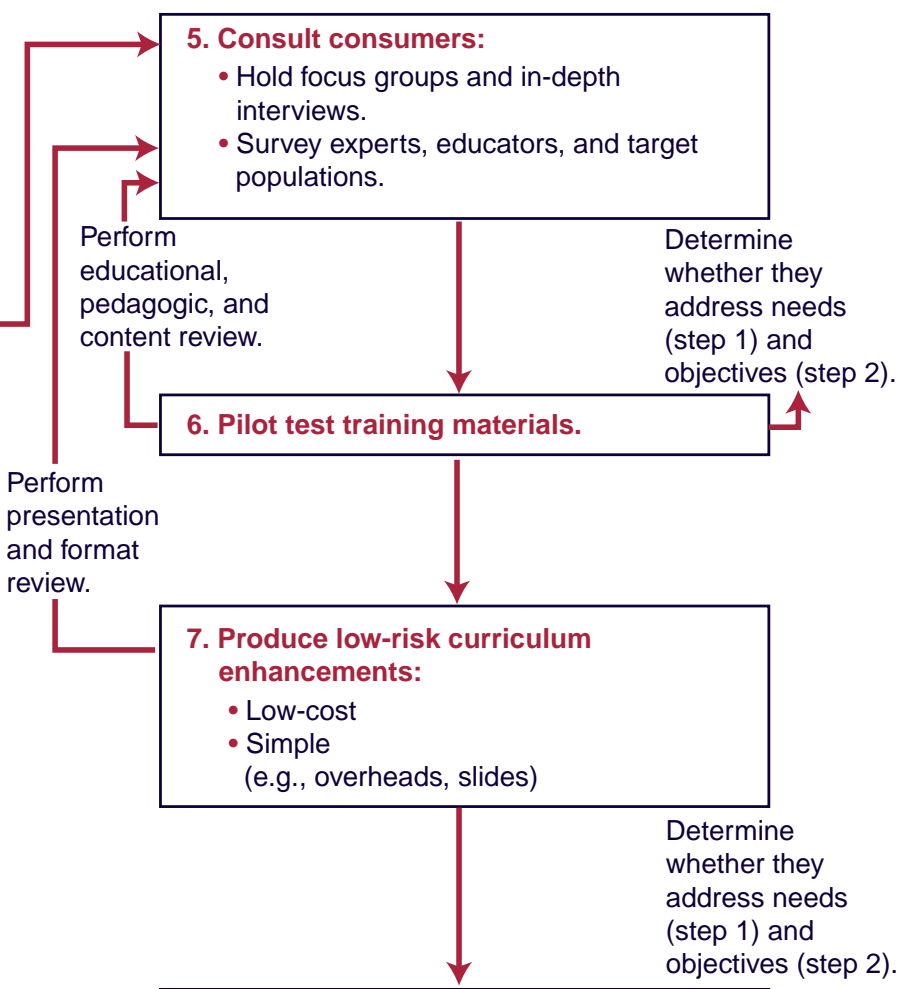

8. Draft research instruments and schedules to address the following:

- Factual knowledge and comprehension

- Beliefs, attitudes, and behavioral intent

- Perception and judgment

- Behavior and practice

Go to Stage 2

Figure 3. Stage 1. Formative research. 
During process research, researchers should continue to consult end users and content experts. The products of Stage 2 are a research report with recommendations and a test curriculum ready for expanded research (see Figure 4).

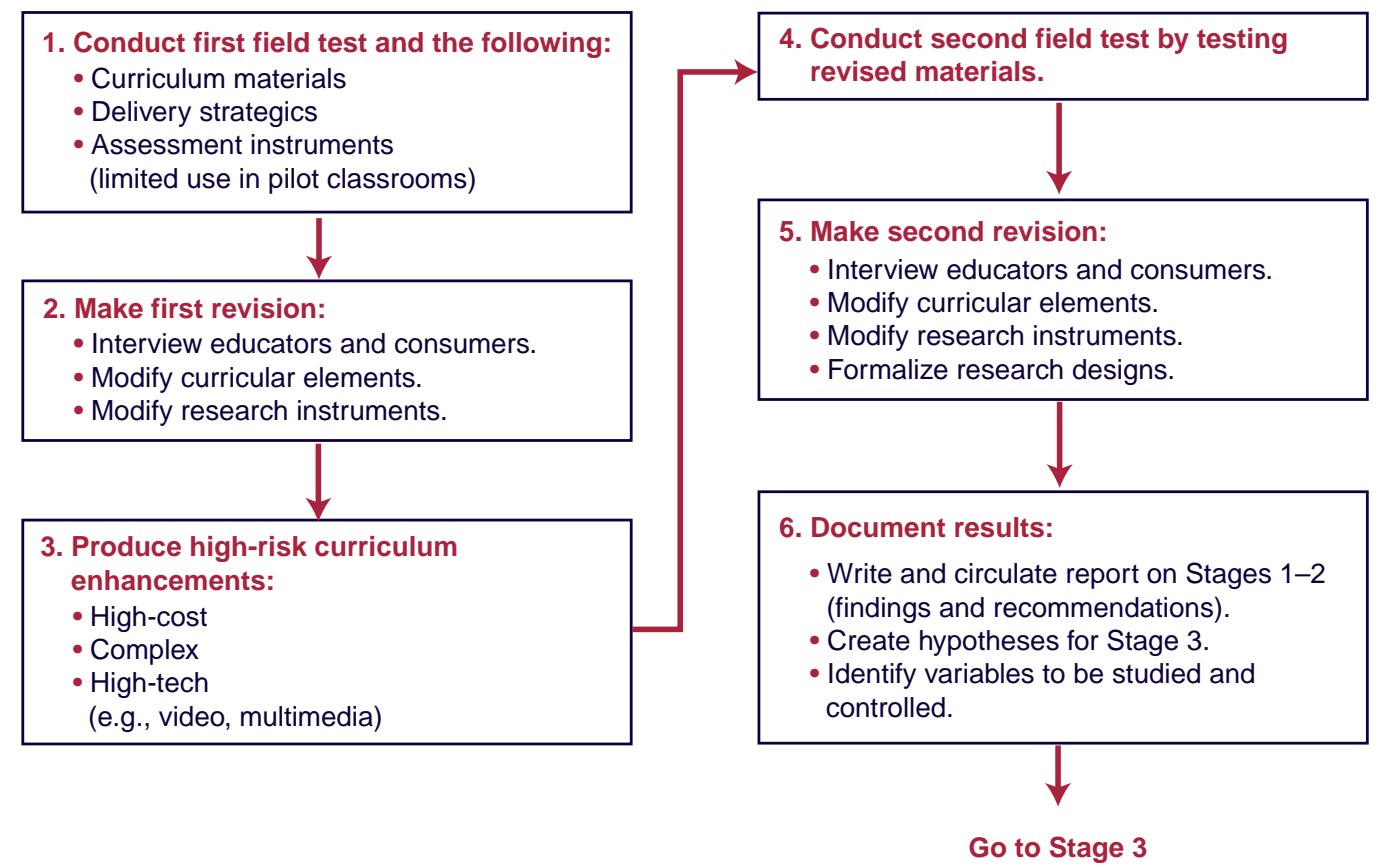

Figure 4. Stage 2. Process research involving field testing.

\section{Stage 3: Outcome Research}

Stage 3 involves a controlled evaluation study. This stage is primarily concerned with the following research questions:

Does the approach produce intended outcomes such as increased knowledge, appropriately shaped attitudes, and positive behavioral intent?

Are targeted behaviors modified?

What are the critical elements of the instructional approach that contribute to desired results?

At the conclusion of this stage, the results of the training effort are documented. These data provide the researcher with improved understanding of the various training approaches that can be applied to (1) the population trained, (2) the subject matter addressed, and (3) the instructional methods used. 
At this time, hypotheses are formulated about critical elements to be explored through future research. Expanded research may entail (1) modifications to the present study, (2) replication of the Stage 3 study using a different trainee population or topic, and (3) assessment of the longitudinal development of initial outcomes (see Figure 5).

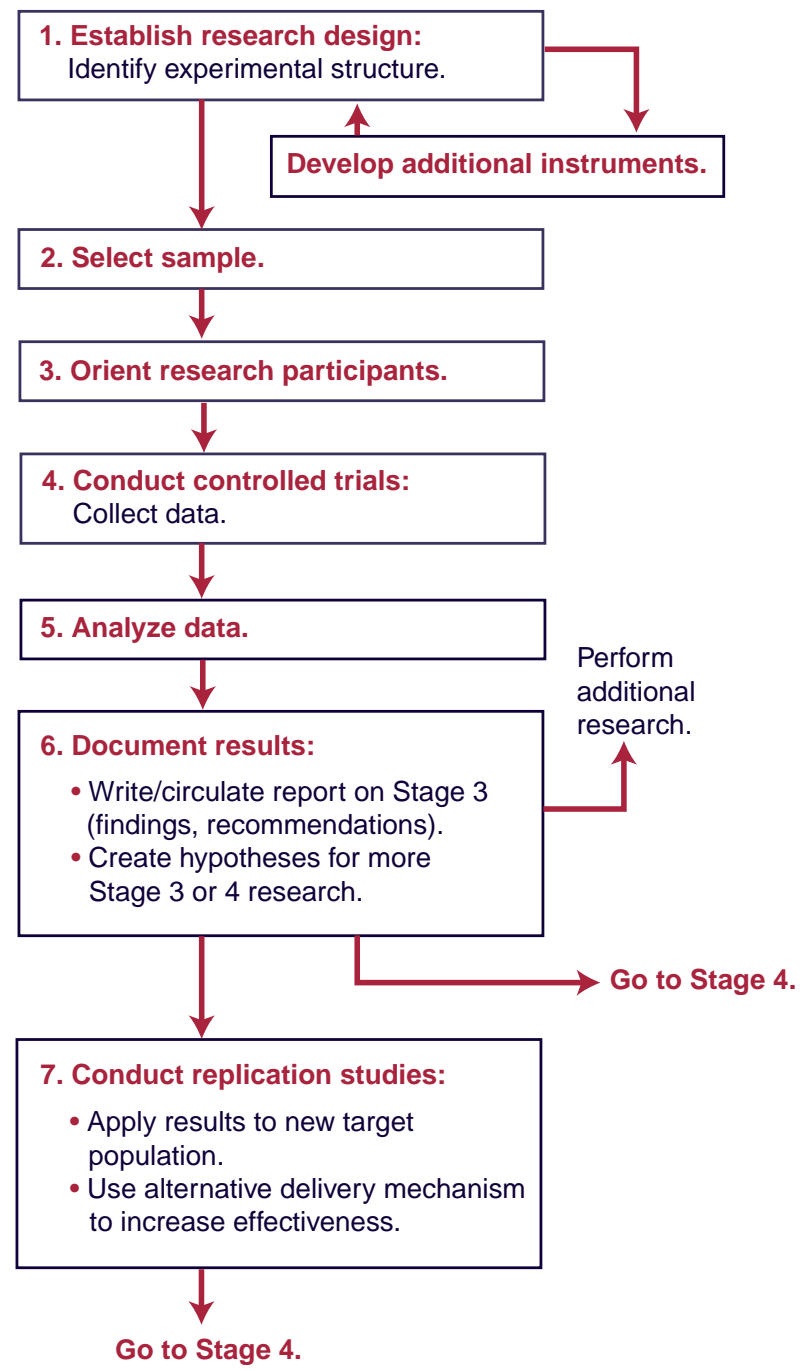

Figure 5. Stage 3. Outcome research involving controlled studies. 


\section{Stage 4: Impact Assessment}

In Stage 4, longitudinal studies are conducted. This final stage emphasizes these research questions:

Do the approaches under study meet the educational needs identified in Stage 1?

What are the intended and unintended impacts of the training on the learner and his or her environment?

What are the direct effects on the learner?

What are the indirect effects on others whom the trainee influences?

Why are the approaches studied effective or not?

Stage 4 will also examine the impact of study-related materials (e.g., model curricula, published reports) as they are applied to practice. The products of Stage 4 research are similar to those of Stage 3 except that the emphasis is on longer-term impacts rather than immediate outcomes (see Figure 6).

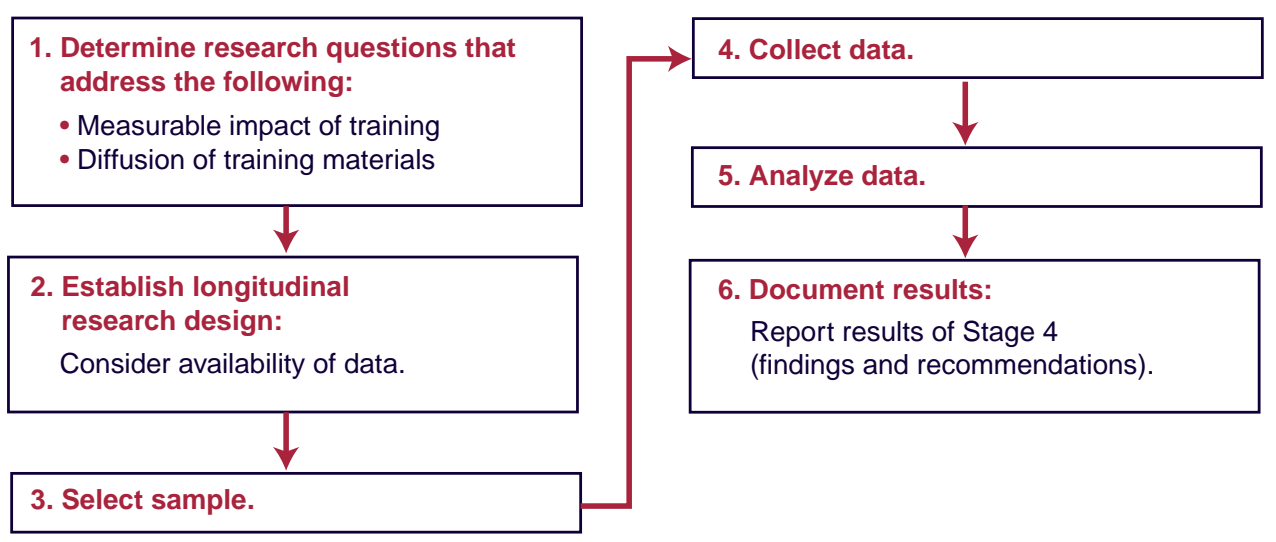

Figure 6. Stage 4. Impact assessment. 
A research project can systematically work through all stages of the TIER model. Alternatively, research can begin or occur at any stage or subset of stages of the model, depending on the state of the training materials and the nature of the research questions [Loos 1995].

Use of the TIER model will refine and focus the efforts of training evaluation studies. The model will also provide researchers with practical knowledge of training research design and consistency, and with a reliable reference point for launching other investigations. Such benefits complement the primary goals of identifying the critical elements of effective training and creating validated templates. 


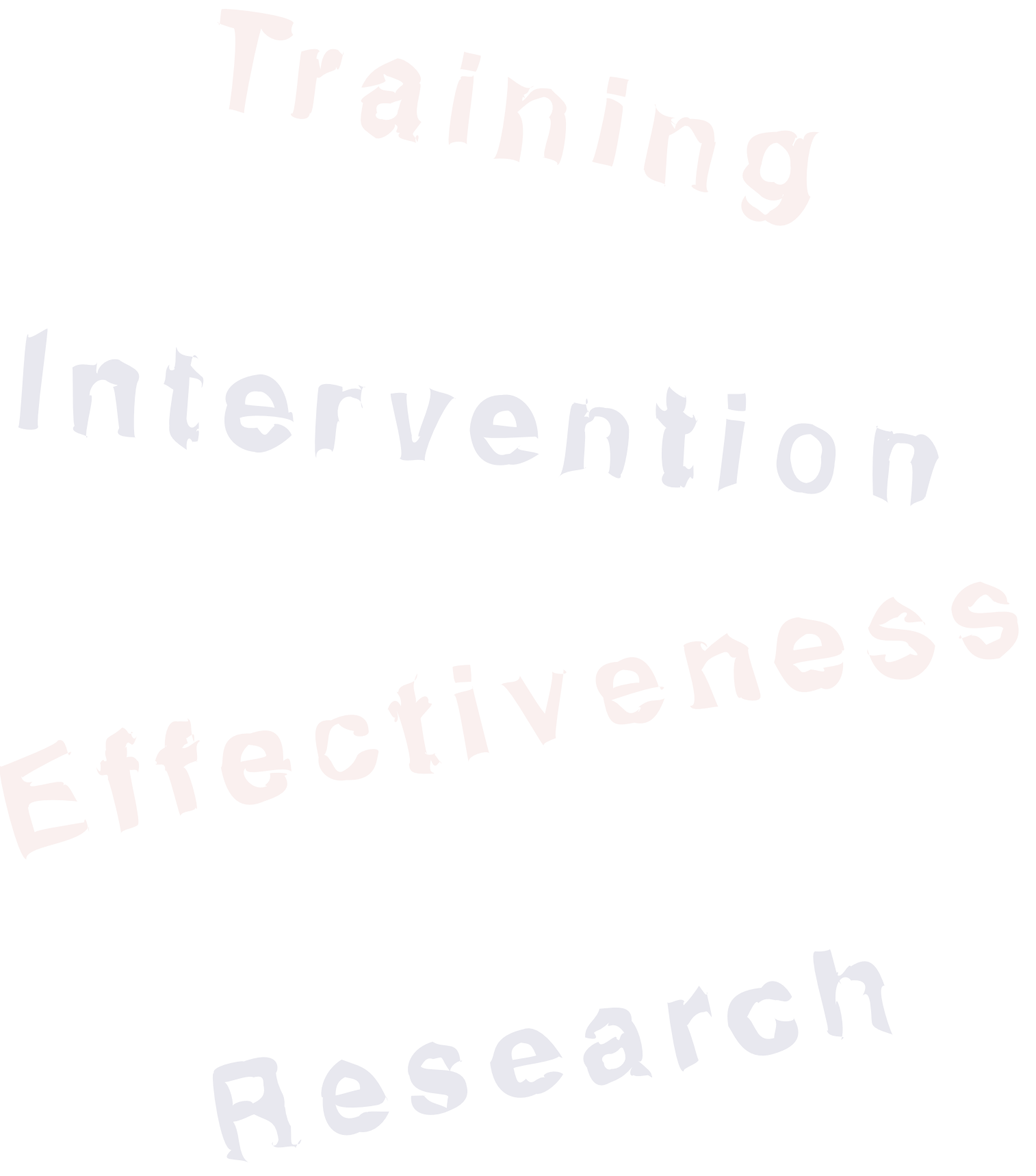




\section{Application of the TIER Model to Occupational Safety and Health Training}

\section{Emerging Issues}

Despite the increased interest in the value and quality of occupational safety and health training, little attention has been given to how to apply this interest. Also, as exemplified by the proposed OSHA Occupational Safety and Health Program Rule (see Figure 7), none of the current initiatives are charged with identifying the recurring elements that make training effective. As noted, multiple variables can influence training effectiveness. The attention given to any single set of variables depends on the purposes of the investigation.

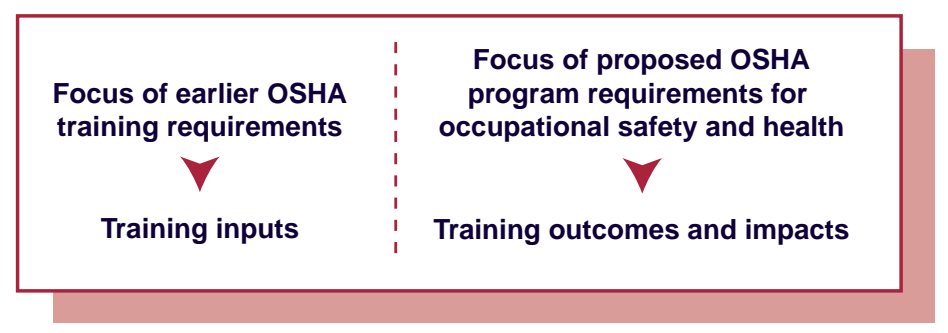

Figure 7. Evaluation of occupational safety and health training.

Application of the TIER model to occupational safety and health training will help determine

—whether different instructional topics require common or different training elements to be taught effectively, and

-how different trainee populations benefit from alternative instructional strategies. 
These determinations are especially useful given that OSHA standards for training cover a multitude of occupations. If certain educational practices are found to improve learning under a variety of circumstances, they can be integrated into holistic workplace safety and health programs across occupational sectors. Greater uniformity of training methods will permit meta-analysis using the TIER model, and will lead to additional strategies for effective training.

Furthermore, training effectiveness studies need to determine

—how different mediums for instruction influence training effectiveness, and

—whether different instructional formats are more efficient for learning.

Twenty years ago, when many workplace and professional occupational safety and health programs were first formalized, the amount of available information doubled every 15 to 20 years. In contrast, within the next 2 decades, information is expected to double every 6 months. Although the rate of doubling may differ across disciplines, inevitably, training programs delivered at one point in time will become dated as new research and experiences modify prior knowledge. Safety professionals and workers must be readied as lifelong learners to fulfill their respective roles in the future of occupational safety and health.

As a global economy becomes reality, workplace training, continuing professional education, and full-degree programs may be needed in distributive formats that can reach learners worldwide. The feasibility of long-distance training will depend on the availability of advanced cognitive learning formats that can transmit quality instruction without exhausting the resources of workplace safety programs and university degree programs. Studies will be needed to assure the quality and effectiveness of these nontraditional learning resources.

For example, on-campus professional programs may be more effective than Internet training delivered to distant students because on-campus students have greater access to physical resources (such as libraries) and faculty. Alternatively, distributive training embedded in work settings, where it can be applied to practical situations, may be more effective than theory-driven classroom training. The TIER model can help ascertain the equivalence or advantage of new and existing approaches and can possibly recommend hybrid training interventions for maximum effectiveness.

A related challenge of a global workforce is geographical: Companies will expect safety personnel to monitor operations across jurisdictions, borders, and cultures. These emerging conditions call for (1) new approaches to workplace inspection and (2) the delivery of training that is equally effective and meaningful for different cultural groups.

Given these developments and the proposed OSHA program rule, training effectiveness studies must consider the influence of different training environments to understand how situational factors modify and confound learning. 
An integrated workplace safety and health program (which includes training as well as complementary hazard controls) might have covariant effects and confounded results. Therefore, the effects of nontraining components of these programs must be isolated to clarify the outcomes and impacts of occupational safety and health training across settings.

Increasingly, businesses are embracing alternative work environments such as work-at-home and flexiplace to cut costs and attract preferred workers. Currently, corporate policies toward safety and health (including the assignment of fault for illness or injury) are imprecise with regard to these alternatives. As nontraditional work stations proliferate, private policy and government regulatory standards may require safety personnel to assure that these environments are safe and that occupational safety and health training is provided.

Future regulations may hold the originating or parent company responsible for monitoring the safety of decentralized or subcontracted work environments. If such requirements are codified, safety and health personnel will need adequate preparation as project managers who are capable of planning integrated safety systems and applying controls at multiple levels and across settings.

Another trend, corporate downsizing, has inherent safety and health implications. For example, personnel shortages coupled with sustained productivity may increase the frequency of workplace injuries. Downsizing has also created circumstances in which safety officers trained in a single discipline are responsible for a wide range of environmental, safety, and occupational health issues.

In this changing occupational climate, occupational safety and health training - whether in the workplace or on the college campus - needs expanded research to meet the demands for safe work environments in a global economy. Considering the growth rate of this economy, especially as world population increases and less-developed countries industrialize, the need for effective and efficient training will only escalate.

\section{Readiness}

The preceding review of issues suggests that additional capacities will be required of safety and health personnel and the workplace programs they develop and conduct. As discussed, professional and worker readiness will necessarily include the following elements: (1) a broad-based perspective on occupational and environmental health, (2) the ability to function as lifelong learners, (3) the knowledge to develop and operate integrated controls across multiple occupational settings, and (4) the capacity to convey safety and health information in a manner that is meaningful to the learner.

To achieve these ends with limited training resources, Loos and Diether [1999] recommend substituting problem-based instruction for content-laden, didactic instruction. Problem-based instruction encourages independent, lifelong learning. Such instruction exposes learners to a 
wider range of information than would likely be covered in a traditional lecture format. Since problem-based learning is self-directed, it is adaptable to students with different learning styles and cultural beliefs. These benefits are equally applicable to professional education and workplace training.

Training-related initiatives from private industry and its partners support the use of the TIER model. Some interested groups encourage hazard awareness as an integral component of minimum competencies for new worker readiness [NSSB 1998]. Others are recommending "criteria for best practices in safety, health and environmental training" [ASSE 1997].

Each of these suggestions for modifying occupational safety and health training requires extensive evaluation studies. The approach to training effectiveness research proffered in this document will lead to uniformity across studies and greater generalization of results. 


\section{References}

ASSE [1997]. Procedures for ANSI accredited standards committee on criteria for best practices in safety, health, and environmental training. Des Plaines, IL: Secretariat, American Society of Safety Engineers.

Borich G [1998]. Effective teaching methods. New York: MacMillan Publishing Co.

CFR. Code of Federal regulations. Washington, D.C.: U.S. Government Printing Office, Office of the Federal Register.

Cohen A, Colligan M [1998]. Assessing occupational safety and health training: a literature review. Cincinnati, OH: U.S. Department of Health and Human Services, Public Health Service, Centers for Disease Control and Prevention, National Institute for Occupational Safety and Health, DHHS (NIOSH) Publication No. 98-145.

Crabtree BF, Miller ML [1992]. Doing qualitative research. Newbury Park, CA: Sage.

DOL [1995]. Training requirements in OSHA standards and training guidelines. Washington, D.C.: U.S. Department of Labor, Office of Cooperative Programs, Occupational Safety and Health Administration.

DOL [1998]. Safety and health programs regulation. Washington, D.C.: U.S. Department of Labor [http://www.oshaslc.gov/SLTC/safetyhealth/index.html]. Date accessed: June 1999.

Dunn R, Griggs SA [1988]. Learning styles: quiet revolution in American secondary schools. Reston, VA: National Association of Secondary School Principals.

Gagné RM [1985]. The conditions of learning and theory of instruction. 4th ed. New York: Holt, Rinehart, Winston.

Industry report [1997]. Training Magazine 34(10):33-75.

Loos G, Diether J [1999]. Accreditation of safety and health programs: strategies to meet domestic and global demand. In: Proceedings of the 1999 Professional Development Conference of the American Society of Safety Engineers. Baltimore, MD: ASSE.

Loos G [1995]. Field guide for international health planners and managers. London: Janus Publications.

Miles MB, Huberman AM [1984]. Qualitative data analysis: a sourcebook of new methods. Beverly Hills, CA: Sage.

Mohr LB [1992]. Impact analysis for program evaluation. Newbury Park, CA: Sage.

NSSB [1998]. Mission statement of the National Skills Standards Board. Washington, D.C.: National Skill Standards Board.

Scriven M [1967]. The methodology of evaluation. In: Tyler RW, Gagne RM, Scriven M, eds. Perspectives of curriculum evaluation. Chicago, IL: Rand-McNally, pp. 39-83.

Scriven M [1991]. Evaluation thesaurus. 4th ed. Newbury Park, CA: Sage.

Tuckman BW [1972]. Conducting educational research. New York: Harcourt, Brace, Jovanovich.

USC. United States code. Washington, DC: U.S. Government Printing Office. 


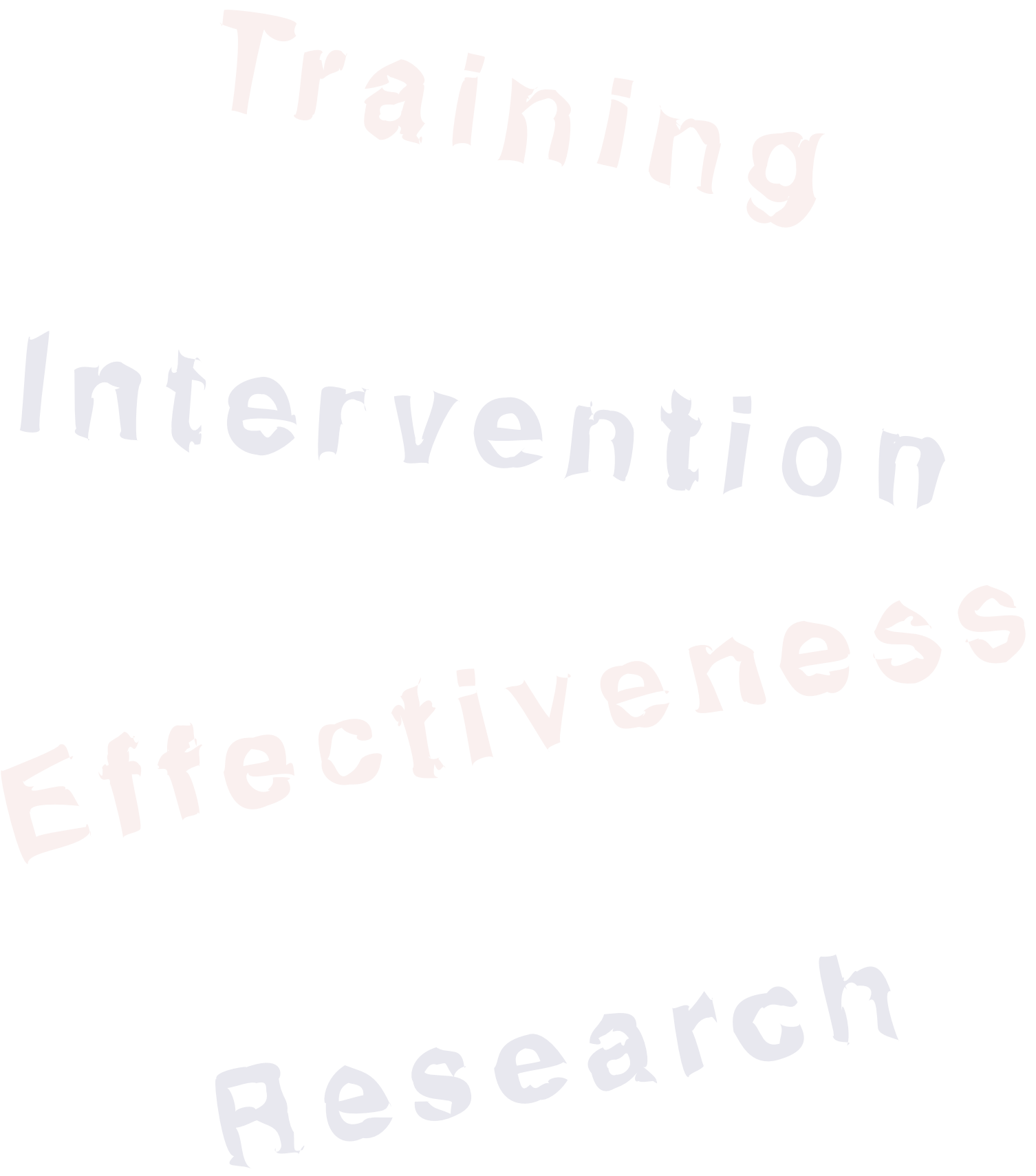



Delivering on the Nation's promise: Safety and health at work for all people through research and prevention

For information about other occupational safety and health concerns, call NIOSH at 1-800-35-NIOSH (1-800-356-4674)

Fax number: (513) 533-8573

E-mail: pubstaft@cdc.gov

or visit the NIOSH Web site at www.cdc.gov/niosh

DHHS (NIOSH) Publication No. 99-142 